\title{
Research on the Application of 3D New Technology Based on Digital Grid
}

\author{
Chunguang Ren ${ }^{1, *}$, Chunhui $\mathrm{Li}^{1}$, Kai Xue ${ }^{1}$, Chao Xue ${ }^{1}$, and Yanbin Han ${ }^{1}$ \\ ${ }^{1}$ Economic and Electrical Research Institute of Shanxi Electrical Power Company of SGCC,030021 Taiyuan City,Shanxi Province,China
}

\begin{abstract}
The strategic goal proposed by State Grid Corporation is to carry out the digital transformation of the power grid. Among them, the value of the digital power grid is to solve the problem of data gaps required for artificial intelligence in all aspects of the power system in the future. The article briefly introduced the current development of 3D design software in the power system and the application direction of new 3D technologies.
\end{abstract}

\section{INTRODUCTION}

As a direction of the intelligent evolution of energy systems, digital power grids are characterized by the application of a large number of sensing, communication, and control components, as well as intelligent decisionmaking in the cloud. The main role played by the digital power grid is to realize the "nervous system" function. The intelligentization of the operation, management and dispatch of the power grid is similar to the "central nervous system". The digital power grid is similar to the "peripheral nervous system", which is "sensed, measured, and measured" by various nerve endings, and also contains some control functions (similar to muscles), nerves (collection and transmission communication), low-level reflex centers (edge intelligent computing), etc. Functional composition. Among them, in terms of technical form, the digital power grid has the characteristics of business value-driven technology applications, end-to-end ubiquitous coverage, and cloudside-end intelligent coordination.Based on the above situation, the design process in the infrastructure business as the data source needs to take 3D design as the leader, engineering data as the core, and 3D technology as the means to establish a full life cycle 3D design platform, and gradually expand the unified data center of the whole business. Standardization and modularization are the means to unify data standards and connect business links to realize data sharing and data incremental operation and maintenance management based on the whole process of project design. Provide a solid data foundation for the practical application of power grid digital applications, form efficient sharing of business data, improve cross-professional collaboration, and realize the transformation of power grid infrastructure business to digital and intelligent.

\section{STATUS QUO}

In foreign countries, three-dimensional design and modeling technology is widely and deeply applied in the BIM field, and it has been widely used in the construction industry's conceptual design, preliminary design, construction drawing and other stages [1]. The IFC standard based on the BIM concept has become a standard for each design profession and each engineering stage to follow each other. IFC standardization also allows the manufacturing industry to transfer the equipment model to the engineering data from the design stage without error, realizing the basis for fine design and ensuring Engineering design quality; in the design phase, the equipment model is calculated and analyzed to complete the construction, the design information is supplemented on the basis of the original model, and the engineering information is digitally transferred; in the construction phase, the construction company can complete collision inspection in advance to reduce rework,carry out construction disclosure and construction simulation to improve construction quality. In China, in 2010, Tsinghua University proposed an extended model of construction management based on BIM design, which links digital design and its construction site 3D model with construction progress in the construction industry, and integrates construction resources and site layout information. It points out the direction for the digital design of the construction industry and the interaction of subsequent life cycle results. In the face of technological progress and the development of smart grids, the State Grid has also put forward urgent requirements for the digital construction of the entire life cycle. In 2016, the State Grid Economic Research Institute conducted a preliminary study on the interaction specifications of 3D design models and formed the version 1.0 of the interaction specification; in 2017, under the organization of the Ministry of

* Corresponding author: 946968143@qq.com 
Infrastructure, the State Grid Economic Research Institute took the lead in the research on the series of specifications for the power grid 3D model, and successively compiled the output specifications. Design guidelines and modeling standards for substations, and form version 2.0 of the $3 \mathrm{D}$ design model interaction specification, which builds a superstructure at the state grid level for 3D collaborative design and interaction with professional design software. [2] This series of specifications is an open criterion. The digital results produced by a substation design platform that meets the specifications can be used interactively through tools to provide interaction between software platforms under the premise of following the specifications. The interaction standards and norms have been established. At present, the design process of the power industry has not been fully three-dimensional, the model building efficiency is low, the engineering calculation methods are primitive, and the whole process of three-dimensional design is still in its infancy.

Through the construction of a three-dimensional design platform for the whole process, the whole process of data achievement and infrastructure construction is covered, and data support is provided for the application of schedule management, safety management, quality management, cost management, technology management, material management, etc. in the process of project construction, involving design and construction Full business units such as, supervisors, manufacturers, etc., realize the electronic, digitized and visualization of project construction information, so as to improve the quality of power transmission and transformation project construction, and improve the level and efficiency of power transmission and transformation project construction.

\section{DISCUSSION ON THE APPLICATION DIRECTION OF 3D TECHNOLOGY}

\subsection{Construction schedule management}

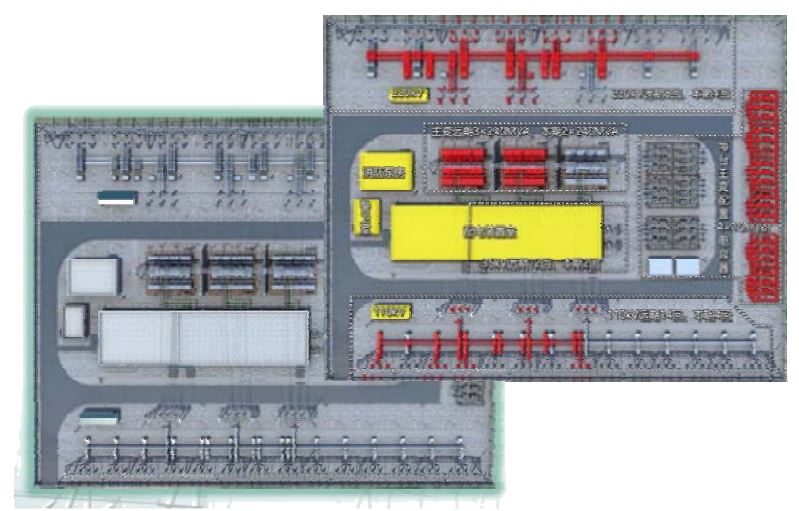

Fig. 1. Construction schedule management.

The presentation of the project construction plan management, actual progress display and progress comparison functions.
Plan management: The project construction plan can be imported into the system, and the plan can also be prepared online;

Actual progress comparison display: The actual progress acquisition method can be divided into the methods of manual online reporting and the generation of the actual progress 3D model, and can be displayed through the comparison of two-dimensional data (such as the horizontal graph, Gantt chart) and the comparison of the three-dimensional model. Plan progress and actual progress, identify progress deviations, and calculate actual progress completion;

Deduction of the construction process: The project owner, supervisor, and construction personnel can deduct the entire construction process in a $4 \mathrm{D}$ sequence through the system.

\subsection{Construction safety management}

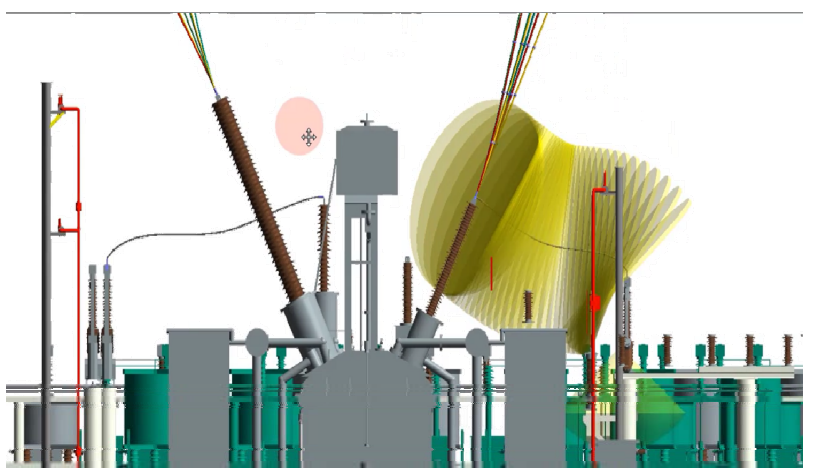

Fig. 2. construction safety management.

Carry out safety management activities in accordance with safety management regulations and safety precontrol measures.

Safety inspection: Complete the closed loop of the system safety inspection process through mobile terminal equipment. The safety management specifications and safety pre-control measures are decomposed into inspection content items. Supervisors conduct inspections at the construction site, record problems, upload image information, and send construction rectifications, rectifications are completed, and supervision review completes the closed loop [3].

Safe and civilized construction: According to the requirements of safe and civilized construction, monitor the form of safe and civilized construction in the construction area, such as wearing work services or wearing helmets, if there is an abnormality, the construction personnel can be reminded through the terminal. At the same time, according to the accumulation of data, the habits and behaviors of the construction workers are analyzed to provide data support for safe and civilized construction management and control.

Safety education and training: In view of the insufficient construction level of the construction personnel, the use of 3D simulation, virtual reality and other technical means, according to the engineering construction standard technology, carry out visual and immersive construction standard technology training to improve the training effect. 
Dangerous area management: the danger source and dangerous area of the construction site, through the deployment of electronic fences, when personnel approach or enter the dangerous area, give an alarm, and promptly remind the personnel to leave the dangerous area.

\subsection{Construction quality management}

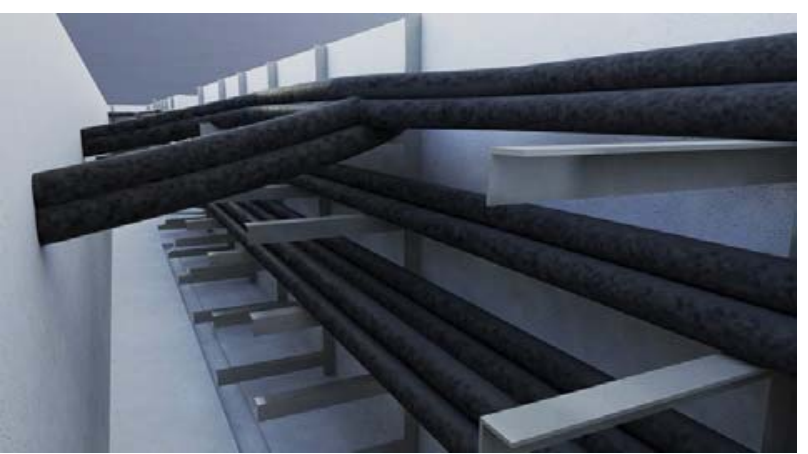

Fig. 3. Construction quality management.

Quality inspection: According to the construction standard process, the system quality inspection is completed through mobile equipment. Supervisors inspect at the construction site, record problems, upload image information, and send the construction rectification, the rectification is completed, and the supervision review is completed to complete the closed loop [4].

Phase acceptance: manage the four periods of project supervision preliminary acceptance, completion preacceptance, completion acceptance and quality supervision and inspection, and the acceptance plan and acceptance report generated in each period, as well as the corresponding digital photos.

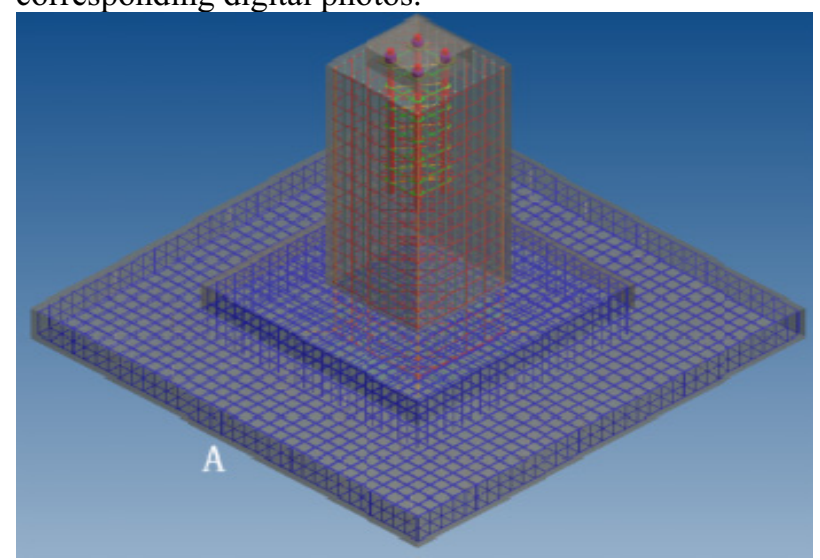

Fig. 4. Construction quality technology management.

Construction drawing review and confession: through the autonomous roaming review in the virtual scene of the construction drawing, the review and confession of the construction drawing is realized.

Electrical test: By recording the results of the electrical test, and recording the participants and the test time, the traceability of test problems is realized。

\subsection{Project cost management}

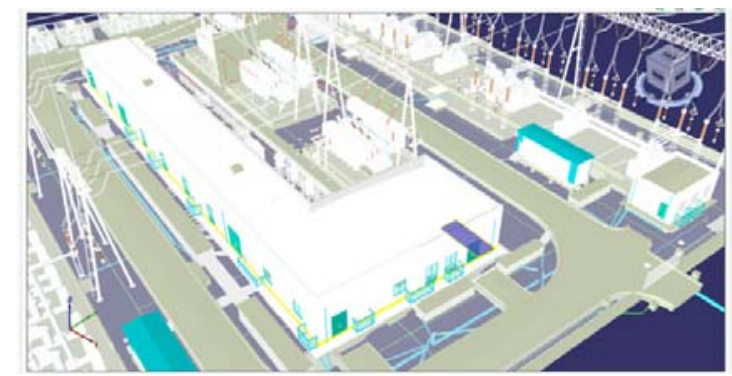

Fig. 5. Project cost management.

Cost management mainly includes: engineering quantity, design change, on-site visa, progress payment application, and settlement.

Engineering quantity list: Import the estimated budget file (including contract budget and cost budget), bind the model after obtaining the estimated budget data, and click on the model to clearly see the contract budget, cost budget and actual cost of the project quantity of the relevant model part Data [5]. Realize three-dimensional automatic calculation and change of volume and price comparison analysis function, which is convenient for cost control.

Project quantity statistics: statistics the data of the project quantity in the list, summarize the contract amount and the cost of design changes and the budgeted cost expenses, by viewing the summary of the data details, check the profit and loss of the three calculations of the list and the three calculations of resources (equipment, materials, people), Saving over conditions, easy to control the cost.

On-site visa contact form: The owner, supervision unit, construction unit, etc. can initiate a contact form, record the suggested content of the contact form, etc., so as to facilitate the initiation of design changes and onsite visas.

Design changes: After the project construction drawings are issued, the design unit makes changes to the design drawings according to the requirements of the construction unit. The content of the changes can be approved and modified level by level in accordance with the standard and standardized process. After the design modification is completed, the modified design will be updated to the model synchronously through the 3D design platform, and the approved design change order will be bound to the 3D model and viewed through the 3D model. The content of the change to realize the synchronization and timeliness of the data.

On-site visa: During the construction process, if the corresponding documents are signed, after the signing is completed, the corresponding data will be recorded; after the completion of the construction, the corresponding signed content will be exported in the corresponding format. The on-site visa is the result of calculating the cost change based on the design change order. In the final settlement of the project, the contract should be the center, and the above three orders involving the change of the contract price should be demonstrated one by one whether the price can be adjusted.

Application for progress payment For the application for expenses incurred during the construction of the 
project, the actual cost of the project is calculated according to the corresponding unit price through the entry of the actual project, and the corresponding amount of progress payment is applied for according to the cost of the project. The approval of progress payment shall be approved level by level in accordance with the standard process.

Settlement: Through the actual costs incurred during the construction process and the costs incurred by design changes calculated in the engineering quantity, the contract, budget and actual costs are counted, and finally the profit and loss of the project and the savings and excess are reflected, which is convenient for cost control.

\subsection{Technology Management}

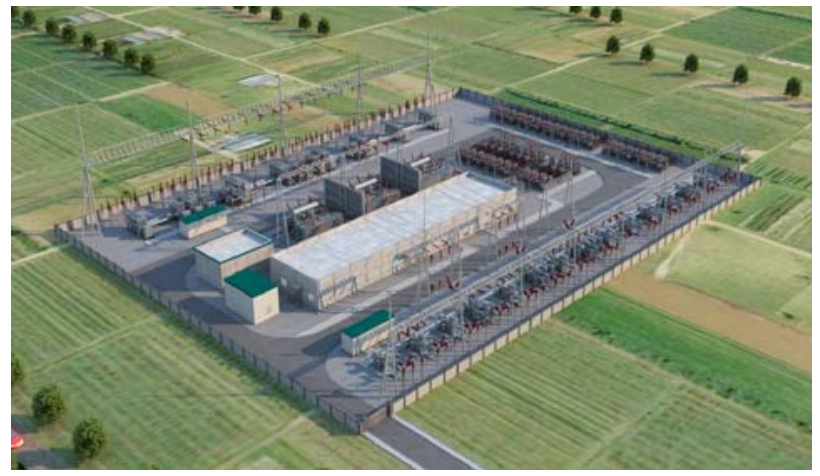

Fig. 6. Technology management.

The main contents of technical management include: construction plans, construction drawings, as-built drawings, equipment and facilities attributes, technological innovation, and mobile technology management [6].

Construction plan: Based on the three-dimensional model, view the equipment and facilities corresponding to the corresponding model, and the relevant construction plan documents that need to be referred to during the construction process.

Construction drawings: You can view the corresponding equipment and facilities of the corresponding model, and the relevant construction drawings referred to in the construction process.

Completion drawings: Perform unified digital management of all completed drawings after the construction of the substation project is completed to ensure the integrity of the transferred data after the completion of the construction.

Equipment and facility attributes: related attributes are bound to the three-dimensional model of equipment and facilities, including electrical attributes, civil construction attributes, personnel attributes, machine tool attributes, safety risks, and quality standard processes.

Technological innovation: mainly to view technological innovation documents[7].

\section{Conclusion}

Through the research of three-dimensional design results, it is gradually transferred, applied and shared in all aspects of the whole process of infrastructure management. Realize the full-process three-dimensional design application, realize the unified management and three-dimensional visualization of the whole life cycle power grid engineering data, and provide basic support for ensuring the company's power grid engineering data security and realizing the sharing of massive engineering information. Through the deep application of threedimensional technology, lean management of the whole process of project construction is realized, and the level of project construction and management is comprehensively improved. Through the efficient sharing of business data, three-dimensional visualization, data sharing, artificial intelligence and other technologies are used to improve the effectiveness of cross-professional collaboration and realize the transformation of power grid infrastructure business to digital and intelligent. To provide a foundation for building a comprehensive digital management platform for the entire process of infrastructure construction and realizing infrastructure management "holographic status awareness, digital engineering management, integration of business collaboration, and intelligent management decision-making"[8].

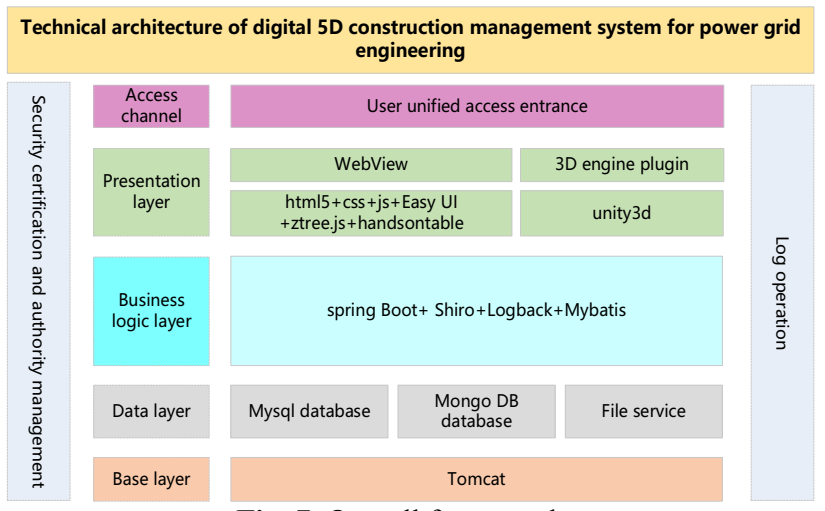

Fig. 7. Overall framework.

\section{References}

1. Wu Wei. Exploration and Implementation of 3D Design Method for Substation[J]. Journal of Electric Power, 2016(12), 31(6): 499-504.

2. Li Hui. Research on Substation Construction Project Management Based on BIM Technology [D]. North China Electric Power University, 2015.

3. Zhai Shudong, Wang Yanmei, Tu Qingbo, $\mathrm{Hu}$ Yuqiang. Three-dimensional modeling of substation based on BIM technology[J]. China Power Enterprise Management, 2016(10): 88-90.

4. Xiang Ling, Shao Junwei, Tan Hailan, Li Sihao. Three-dimensional collaborative design of intelligent substation [J]. China Electric Power (technical version), 2012 (11): 454-459.

5. Li Yingwei, Li Bo, Li Shaosheng. Discussion on Application of 3D Design of Substation[J]. China Electric Power Industry Co., Ltd., 2012(4):26-28. 
6. Li Feng, Tang Wei, Nie Lei. Discussion on 3D Collaborative Design of Outdoor Substation[J]. For Electricity Supply, 2013(02): 46-50.

7. $\mathrm{Li}$ Jianbo, $\mathrm{Mu}$ Huaqian. Analysis of BIM collaborative design of building electrical based on REVIT[J]. Intelligent Building Electrical Technology, 2015(01): 8-11.

8. Li, J. F. Xiong, S., \& Gao, F. Application and research of kinect motion sensing technology on substation simulation training system. Journal of Rare Earths, 33(8) (2015) 800-804. 